DOI 10.37882/2223-2982.2021.04-2.17

\title{
РОЛЬ ОТКРЫТОЙ ОЛИМПИАДЫ ШКОЛЬНИКОВ ПО ХИМИИ В ФОРМИРОВАНИИ ГОТОВНОСТИ К ОБУЧЕНИЮ В ВУЗЕ
}

\section{ROLE OF THE OPEN CHEMISTRY OLYMPIAD IN FORMING READINESS FOR LEARNING AT THE UNIVERSITY}

T. Kolosova

L. Kubasova I. Sychev

Summary: The article discusses the problem of forming the psychological readiness of applicants to study at a medical university. The most important components of readiness are noted: intellectual and motivational. The necessity of the coordination of educational programs of the school and the university is shown, which can be achieved by the implementation of special projects of pre-university training in specialized subjects, including chemistry. The use of the Open Subject Olympiad for schoolchildren is considered as one of such projects and its definition is given as an innovative pedagogical technology. A conclusion is drawn about the role of the Open Olympiad in the formation of the intellectual and motivational components of readiness to study at a university.

Keywords: readiness for learning, intellectual readiness, motivational readiness, Olympiads of schoolchildren.
Колосова Татьяна Юльевна К.Х.н., доцент, ФГБОУ ВО РязГМУ Минздрава России (2. Рязань)

tkkolosova@gmail.com

Кубасова Лариса Владимировна к.фрарм.н., доцент, ФГБОУ ВО РязГМУ Минздрава России (2.

Рязань)

larissa.k53@mail.ru

Сычев Игорь Анатольевич

д.б.н., ФГБОУ ВО РязГМУ Минздрава России (г. Рязань) i.sytchev@rzgmu.ru

Аннотация: В статье обсуждается проблема формирования психологической готовности абитуриентов к обучению в медицинском ВУЗе. Отмечены важнейшие составляющие готовности: интеллектуальная и мотивационная. Показана необходимость согласованности образовательных программ школы и ВУЗа, которая может быть достигнута реализацией специальных проектов довузовской подготовки по профильным предметам, в том числе по химии. Рассмотрено использование Открытой предметной олимпиады школьников в качестве одного из таких проектов и дано ее определение как инновационной педагогической технологии. Сделан вывод о роли Открытой олимпиады в формировании интеллектуальной и мотивационной составляющих готовности к обучению в ВУЗе.

Ключевые слова: готовность к обучению, интеллектуальная готовность, мотивационная готовность, Олимпиады школьников.

ет выпускнику средней школы участвовать в учебнопрофессиональной деятельности, мобилизуя все свои ресурсы и ориентируя свое поведение на выполнение учебных задач, заниматься самостоятельной познавательной деятельностью и поиском новой информации, выдвигать новые идеи [1,2].

Для ее успешного формирования необходимо обеспечить преемственность и согласованность образовательных программ школы и ВУЗа. Для этого в ВУЗе реализуются специальные программы довузовской подготовки по профильным предметам, которые используют различные современные образовательные технологии, в том числе Открытые олимпиады школьников. Отметим, что Олимпиада школьников - это инновационная педагогическая технология, заключающаяся в творческом состязании школьников в креативном применении знаний, теоретических и практических способах деятельности в различных предметных областях $[3,4]$.

Актуальность данного исследования обусловлена недостаточностью данных о влиянии внедрения технологий олимпиад в систему довузовского образования на успешность абитуриентов и успеваемость студентов- 
первокурсников.

\section{Ше^ь}

Целью данной работы является анализ роли Открытой олимпиады по химии в системе довузовской подготовки учащихся старших классов в формировании психологической готовности к обучению в медицинском ВУЗе.

\section{Материалы и методы}

При проведении Открытой олимпиады по химии использовались инновационные образовательные технологии: проблемные теоретические задания отборочного и заключительного туров, кейс-задания экспериментальной части заключительного тура, электронная образовательная среда ВУЗа, позволяющая школьникам регистрироваться для участия в олимпиаде и дистанционно выполнять задания отборочного тура.

\section{Результаты и их обсужАение}

В рамках реализации программ довузовской подготовки по профильным предметам в Рязанском государственном медицинском университете имени академика И.П. Павлова в 2018-19 и 2019-20 учебных годах проводилась Открытая олимпиада школьников по химии. Участниками олимпиады выступали школьники 10 и 11 классов средних школ из различных субъектов Российской Федерации, как из Рязанской области, так и из удаленных регионов.

Отборочный этап Открытой олимпиады проходил в дистанционном формате, который предполагал выполнение школьниками разнообразных заданий: написание цепочек химических превращений, идентификация неизвестного вещества по его свойствам, решение расчетных задач, обсуждение проблемы и поиск ее решения. Время на выполнение отборочного тура было ограничено восемью часами, а информационно-образовательная среда нашего ВУЗа позволяла выполнять задания дистанционно в выбранное самим участником время. Заключительный тур Открытой олимпиады проходил в аудиториях Рязанского государственного медицинского университета для победителей и призеров отборочного тура в очном формате. Школьникам предлагались теоретические задания, связанные с идентификацией и синтезом веществ, с выполнением расчетов по химическим реакциям, с решением различных химических проблем. Экспериментальные задания представляли собой кейсзадачи на идентификацию и количественное определение веществ.

Банк заданий Открытой олимпиады по химии содержал вопросы всех разделов школьного курса.
Основная функция Открытой олимпиады - образовательная - способствует формированию интеллектуальной составляющей психологической готовности к обучению. Для успешного участия в олимпиаде школьнику необходимо самостоятельно решить большое количество нестандартных задач, а также задач повышенной сложности, выходящих за рамки школьной программы, что требует высокой скорости чтения и письма, навыков работы с текстом, быстрого переключения внимания. Олимпиады любого уровня оценивают уровень сформированности системных знаний школьника по химии, способствуют более глубокому и прочному усвоению знаний, совершенствуют его системное мышление, умение обрабатывать информацию и выделять главное, содействуют саморазвитию его личности $[5,6]$. Использование в заданиях отборочного и заключительного туров современных проблемных и кейсовых образовательных технологий развивает самостоятельность в обучении, так как требует анализа ситуации, прогнозирования, планирования, необходимости делать выбор и принимать решение [7].

Для анализа роли Открытой олимпиады в формировании интеллектуальной составляющей психологической готовности использовался критерий наличия необходимого уровня сформированности знаний, умений и навыков, специфичных для учебной деятельности студентов. Нами было проведено сравнение образовательного уровня абитуриентов, поступивших в РязГМУ на лечебный факультет в приемную кампанию 2020 года. Среди них мы выделили следующие группы: победители Открытой олимпиады, призеры Открытой олимпиады, остальные участники заключительного тура и все абитуриенты. Численность групп составила, соответственно, 6, 13, 36 и 535 человек. Для анализа были высчитаны средние суммарные баллы ЕГЭ среди абитуриентов этих групп.

Результаты сравнения представлены на рисунке 1. Как видно из диаграммы, школьники-победители и школьники-призеры Открытой олимпиады набрали при поступлении значительно больше баллов (263 и 255), чем в среднем по всем абитуриентам, поступившим на лечебный факультет (220). Средний балл ЕГЭ остальных участников заключительного тура, не ставших победителями и призерами, (244) также существенно выше среднего значения по всем абитуриентам (220).

Также нами был проведен сравнительный анализ успеваемости студентов лечебного факультета 1 курса в 2020-21 учебном году по дисциплине Общая химия в тех же группах: победители и призеры Открытой олимпиады, остальные участники заключительного тура и все студенты, - анализ баллов ЕГЭ, которых был выполнен выше. Успеваемость определялась как доля студентов, успешно выполнивших промежуточные контроли по 


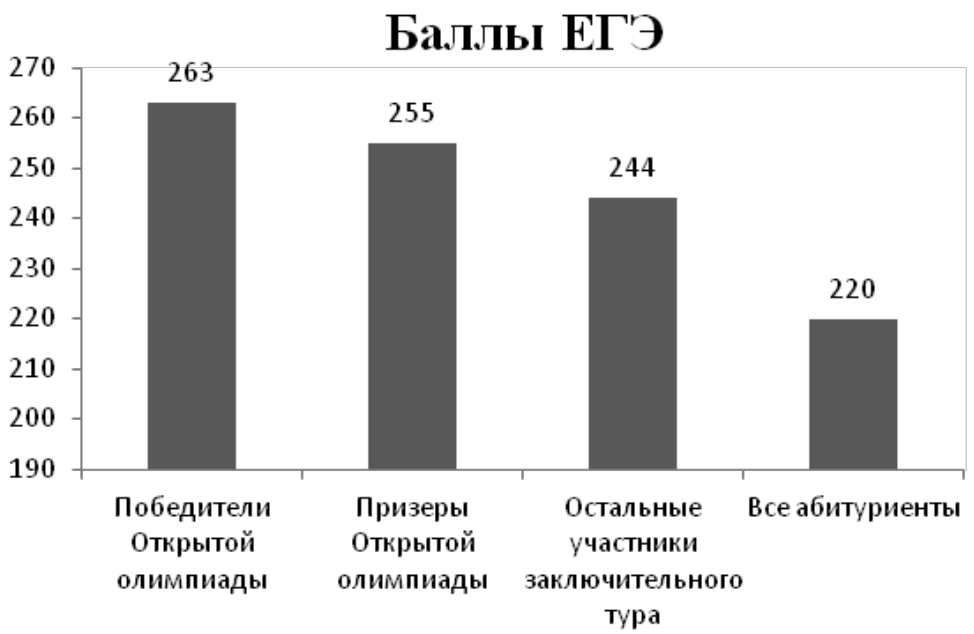

Рис. 1. Баллы ЕГЭ по группам абитуриентов в приемной кампании 2020 года

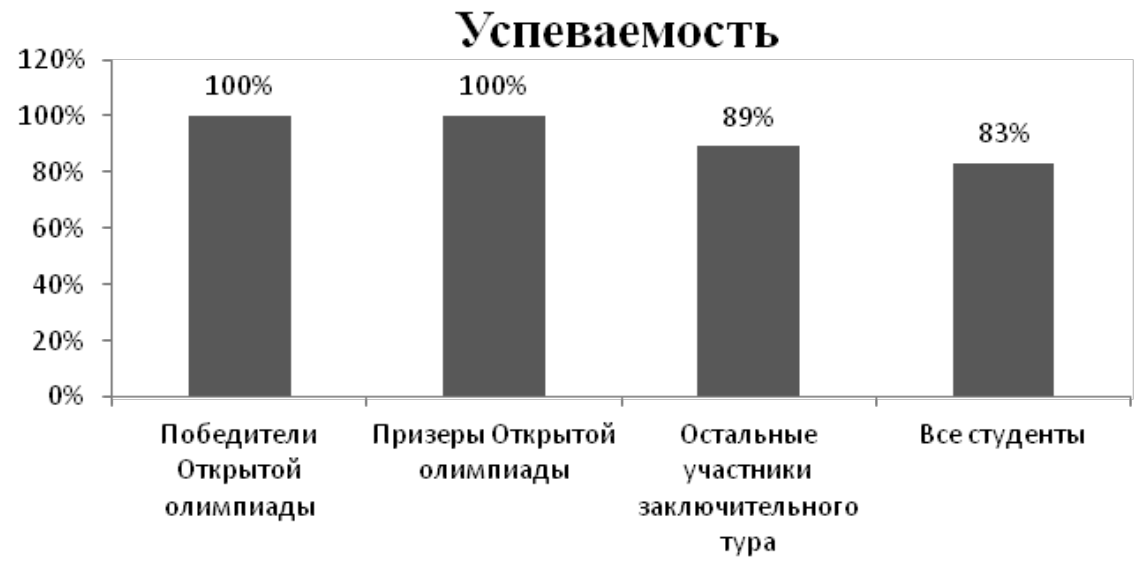

Рис. 2. Успеваемость студентов 1 курса лечебного факультета по дисциплине Общая химия в первом семестре 2020-21 учебного года

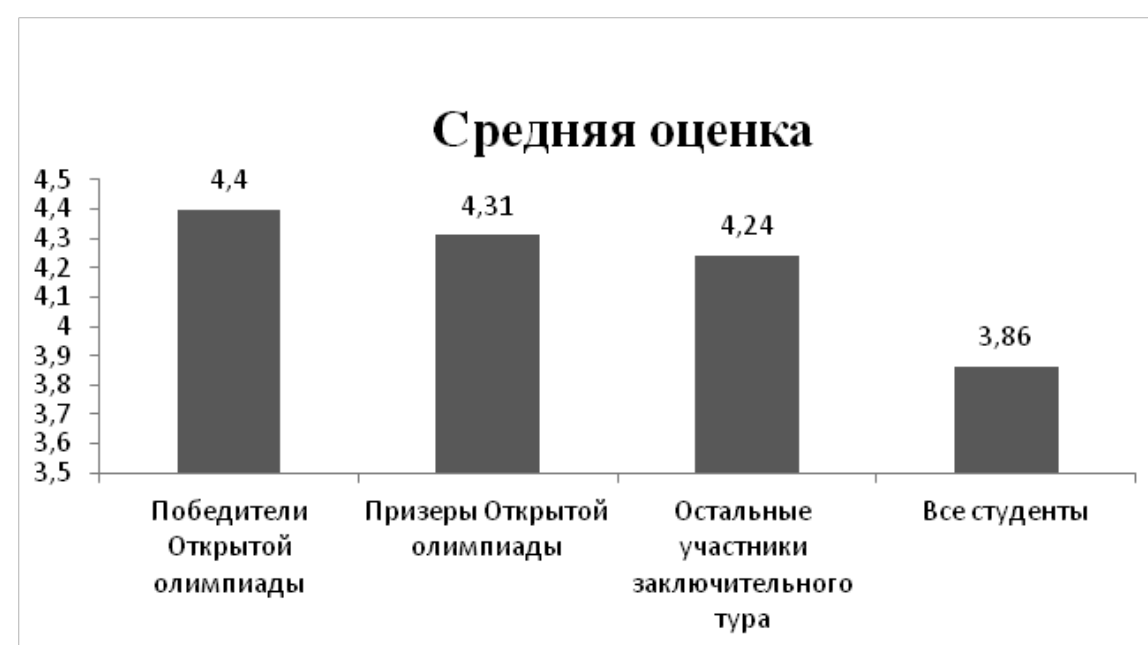

Рис. 3. Средняя оценка итогового контроля по дисциплине Общая химия 
данной дисциплине во временных рамках текущего семестра.

Результаты сравнения представлены на рисунке 2. Как видно из диаграммы, студенты - победители и призеры - имеют 100\% успеваемость. Результат среди студентов - остальных участников заключительного тура ниже и равен 89\%. Средняя успеваемость всех студентов 1 курса составляет $83 \%$.

Анализ оценок (в пятибалльной шкале) итогового контроля по дисциплине Общая химия, полученных студентами лечебного факультета 1 курса в зимнюю сессию, показан на Рисунке 3. Средняя оценка студентов - победителей, призеров и участников заключительного тура олимпиады (4,24 балла и более) значительно превышает среднюю оценку всех студентов $(3,86)$.

Таким образом, Открытая олимпиада как современная педагогическая практика развивает интеллектуальную составляющую психологической готовности к обучению. Она способствует формированию знаний, умений и навыков, необходимых для дальнейшего освоения химических дисциплин (Общей химии, Биоорганической химии, Биологической химии) и для последующего успешного профессионального обучения в ВУЗе, и, как следствие, повышает качество профессиональной подготовки студентов.

Отметим, что Олимпиады - это мощный фактор формирования мотивационной составляющей готовности к обучению [8,9]. Мотивационная компонента представляет собой желание быть студентом и выполнять обязанности в соответствии с новым статусом, для чего школьник должен владеть исчерпывающей информацией о будущей профессии, осознавать свой выбор окончательным на данном этапе жизни и иметь желание учиться.

Открытая олимпиада школьников по химии, проводимая в РязГМУ имени И.П. Павлова, вошла в перечень олимпиад, утвержденный Приказом Минпросвещения
России от 11.12.2020 № 715 «Перечень олимпиад и иных интеллектуальных конкурсов, направленных на развитие интеллектуальных и творческих способностей, способностей к занятиям физической культурой и спортом, интереса к научной (научно-исследовательской), инженерно-технической, изобретательской, творческой, физкультурно-спортивной деятельности, а также на пропаганду научных знаний, творческих и спортивных достижений, на 2020/21 учебный год». Сведения о победителях и призерах олимпиад школьников вносятся в государственную информационную систему «Ресурс об одаренных детях».

Для школьника это означает, что победители и призеры Открытой олимпиады РязГМУ могут рассчитывать на получение дополнительных баллов при поступлении в ВУЗы страны, где учитываются результаты по химии. В нашем университете победителям дополнительно начислялось 8 баллов, призерам - 7 баллов, а остальным участникам заключительного этапа - 5 баллов.

Открытая олимпиада играет значимую роль в профессиональной ориентации школьников, позволяя им осуществить осознанный выбор специальности врача и реализовать его, поступив в медицинский ВУЗ [10]. Из 125 участников заключительного тура Открытой олимпиады по химии в 2020 году 55 абитуриентов поступили на лечебный факультет (44\%), 4 - на медико-профилактический факультет (3\%), 13 - на педиатрический факультет (10\%) и 7 - на стоматологический факультет (6\%).

\section{Зак^ючение}

Суммируя вышесказанное, можно сказать, что Открытая олимпиада, создавая условия для всестороннего развития интересов и способностей талантливых школьников, формирует важнейшие составляющие психологической готовности к обучению в ВУЗе: интеллектуальную и мотивационную, и способствует профессиональному самоопределению старшеклассников.

\section{ЛИТЕРАТУРА}

1. Захарова Н.М., Степанова Л.А. Мотивация абитуриентов к поступлению в медицинский институт как показатель готовности к обучению // Вестник Северо-Восточного федерального университета им. М.К. Аммосова. Серия: Медицинские науки. 2017. №1(06). С. 112-116

2. Лызь Н.А., Нещадим И.О. Мотивация поступления в ВУЗ как фактор компетентностно-ориентированного обучения // Вестник ЮУрГУ. Серия «0бразование. Педагогические науки». 2018. Т.10, № 1. С. 13-19

3. Баковецкая 0.В., Камаева С.А., Калыгина Т.А., и др. Открытая олимпиада школьников по биологии как современная педагогическая технология профориентационной работы в медицинском ВУЗе // Личность в меняющемся мире: здоровье, адаптация, развитие. 2020. Т. 8, №1 (28). С. 25-33

4. Скотникова А.М. Олимпиада как психолого-педагогическая технология обучения в ВУЗе // Педагогическое образование в России. 2013. №4. С. 229-237

5. Вахитова Г.Х. Предметные олимпиады как способ повышения качества образования студентов педагогических ВУЗов // Научно-педагогическое обозрение. 2013. 1(1). С. 36-39

6. Малинин В.А., Повшедная Ф.В. Развитие интеграционного процесса в системе «школа - ВУз» в условиях современного образования // Мир науки, культуры, образования. 2012. №5 (36). С. 118-121 
7. Забелина Н.А., Петрова Е.А. Особенности работы с одаренными детьми (на материале английского языка) // Ученые записки. Электронный научный журнал Курского государственного университета. 2019. №1 (49)

8. Дьяченко Е. В., Медведев С. А. Готовность студентов первого курса к освоению врачебной специальности: взгляд психолога //Вестник уральского государственного медицинского университета. 2015. 2-3 (29-30).С. 94-97

9. Луцкова Л.Н., Русина Н.А. Исследование факторов, влияющих на учебную мотивацию студентов медицинского ВУЗа // Медицинская психология в России. 2012. № 2(13).

10. Назарова 0.А., Маркова И.С., Жбанов Н.С. Воспитание молодежи в духе высокоразвитой личности в Рязанском государственном медицинском университете имени академика И.П. Павлова // Личность в меняющемся мире: здоровье, адаптация, развитие: сетевой журн. 2017. Т. 5, №1(16). С. 101-112

( К Колосова Татьяна Юльевна (tkkolosova@gmail.com), Кубасова Лариса Владимировна (larissa.k53@mail.ru), Сычев Игорь Анатольевич (i.sytchev@rzgmu.ru)

Журнал «Современная наука: актуальные проблемы теории и практики»

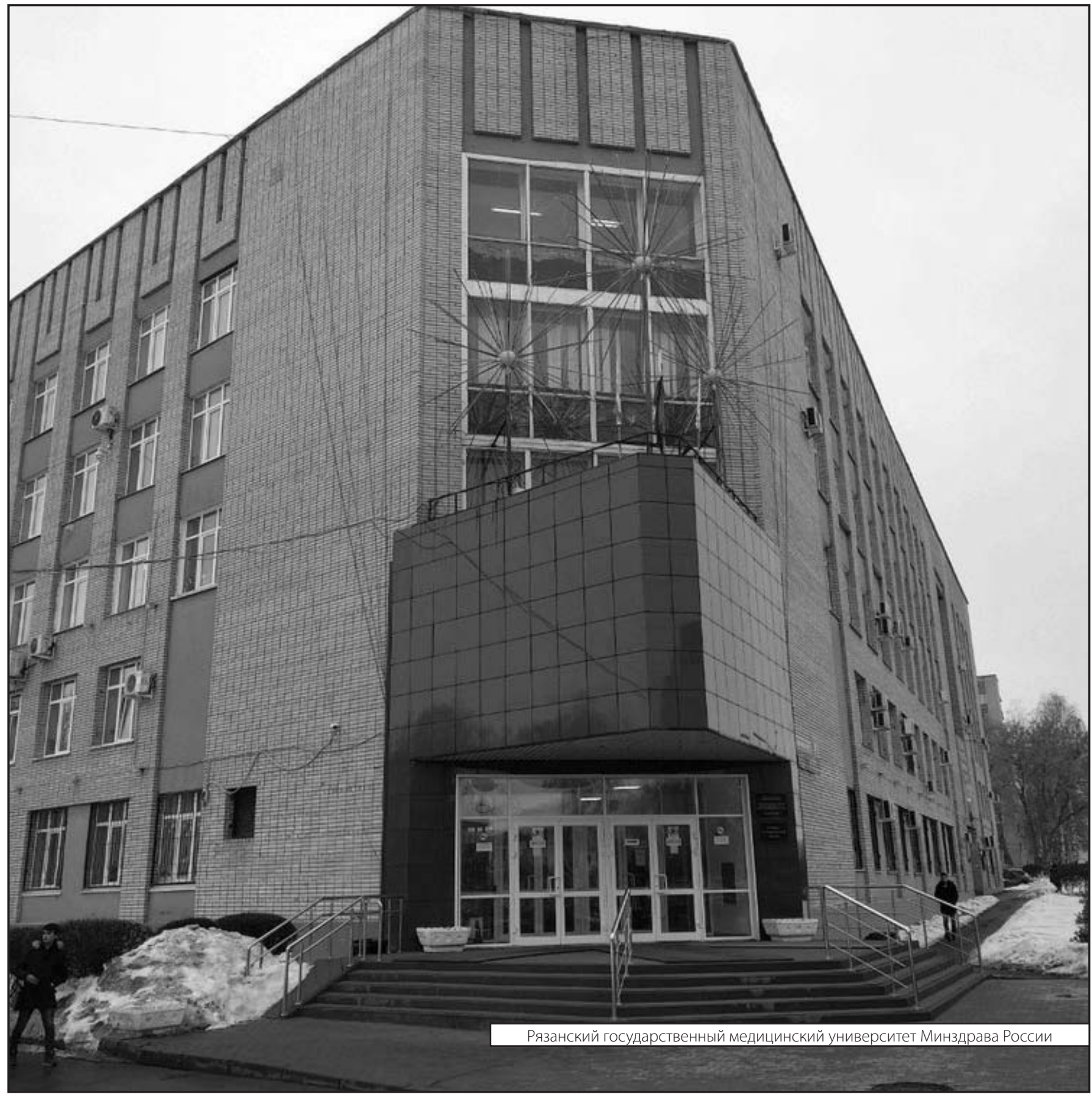

